\title{
Advantages of New Hemodialysis Membranes and Equipment
}

\author{
R. Vanholder G. Glorieux W. Van Biesen \\ Renal Division, Department of Internal Medicine, University Hospital, Gent, Belgium
}

\section{Key Words}

Hemodiafiltration $\cdot$ Dialysis membranes $\cdot$ Protein-bound

solutes - Middle molecules $\cdot$ Uremic toxicity .

Cardiovascular complications

\begin{abstract}
Chronic kidney disease is characterized by the progressive retention of a number of compounds, several of which have the potential to cause cardiovascular damage. Many of these are difficult to remove by standard dialysis strategies. Removal of the larger middle molecules (mostly larger peptidic compounds) can be obtained by increasing dialyzer pore size and/or by applying convective strategies. For proteinbound solutes, convection (essentially hemodiafiltration) positively affects removal. The HEMO study demonstrated outcome superiority for the large-pore high-flux hemodialysis membranes in a number of subgroup analyses. Likewise, the Membrane Permeability Outcome study showed outcome superiority for high flux in patients with serum albu$\min <4 \mathrm{~g} / \mathrm{dl}$, the group for which the study had originally been designed. Apart from a small controlled trial, data suggesting superiority for convective strategies are all observational.

Copyright $\odot 2009$ S. Karger AG, Basel
\end{abstract}

\section{The Uremic Syndrome and Uremic Toxicity}

As chronic kidney disease (CKD) progresses, a gradual dose-dependent dysfunction of most organ systems occurs, called the uremic syndrome [1]. This ultimately results in the malfunctioning of the entire body, and as symptoms become more and more prominent, survival and quality of life can only be maintained by replacing kidney function by dialysis or transplantation.

This set of functional disturbances is attributed to a large extent to the retention of uremic solutes, which, with normal renal function, are removed from the body by the normal kidneys via the urine.

The uremic syndrome consists of a myriad of functional disturbances, such as anemia, metabolic bone disease, insulin resistance, inflammation, hypercoagulation, fluid overload and hypertension. All these, however, cumulate in the most concerning one: cardiovascular disease, which, among the population with end-stage renal failure, remains responsible for more than $50 \%$ of mortality.

For a long time, the nephrological community has focused on cardiovascular disease in patients already on dialysis [2, 3], but later epidemiological work emphasized that the increase in cardiovascular risk already occurred much earlier during the evolution of CKD [4], according to some studies, even from a glomerular filtration rate (GFR) of $90 \mathrm{ml} / \mathrm{min}$ on [5]. As a consequence, major

Prof. Dr. Raymond Vanholde

Renal Division, University Hospital

De Pintelaan 185

BE-9000 Gent (Belgium)

Tel. +32 9332 4525, Fax +32 9332 4599, E-Mail raymond.vanholder@ ugent.be 
guideline-generating bodies such as the Kidney Disease Improving Global Outcomes (KDIGO) or the Kidney Disease: Outcomes Quality Initiative (K/DOQI) restructured the staging process of CKD with an emphasis on the fact that long before the need to start dialysis, earlier stages of CKD also affect outcome $[6,7]$.

As a consequence, the group of physicians involved with patients at risk for CKD also evolved from being composed almost entirely of nephrologists to a much broader group active in preventive screening (occupational medicine), general practice, and specialties frequently confronted with renal failure as complication or cause of the primary condition with which they deal (cardiologists, endocrinologists, vascular surgeons, geriatricians).

CKD is now generally accepted as one of the important cardiovascular risk factors, with a similar impact on outcome as diabetes mellitus. Early screening and identification as well as the institution of preventive measures have become germane aspects of an efficient approach to this condition, which affects a substantial fraction of the general population [8].

Nevertheless, it also became clear that renal cardiovascular disease could not be attributed to an association with traditional risk factors alone. The development of a uremic milieu resulting in inflammation and vascular damage has been suggested as one of the most likely additional culprits $[9,10]$.

In addition, cardiovascular disease may have a different connotation in the early stages of CKD (stages 3 to 4 ) as compared to the end stage (dialysis, CKD stage 5D). Whereas mortality at the early stages is largely due to cardiovascular events like in the general population (e.g. coronary artery disease, acute myocardial infarction, stroke), sudden cardiac death, volume overload and arrhythmias are markedly more prominent in the hemodialysis population which is more prone to these events due to repetitive and sometimes brisk changes in volume status.

\section{Uremic Toxin Retention}

Retention of uremic solutes starts from the moment kidney function declines. The kinetics of this process are, however, far from clear. In addition, although during the last few years an immense progress has been made in the identification and quantification of uremic solutes [11], a large number of retention solutes remain unidentified [12]. An additional handicap in the process of mapping uremic toxicity is the presence of an indefinite number of posttranscriptional modifications of retention solutes, as a result of oxidation, glycation, cysteination, as well as of several other potential chemical processes; with each of these structural variants, the possibility of a pathophysiologic impact that differs from the mother compound should be considered.

As a consequence, the picture of uremic retention has become more and more kaleidoscopic; on the other hand, the notion that several compounds and/or their functional role remain unknown makes further identification and classification compulsory before a targeted and possibly also tailored treatment will be possible.

For the time being, uremic solutes are preferentially classified according to the physicochemical characteristics affecting their clearance during dialysis which, as of today, is still the main therapeutic option for their removal. Traditionally, this subdivision focuses on 3 types of molecules: the small water-soluble compounds (molecular weight $(\mathrm{MW})<500 \mathrm{Da}$ ), the larger 'middle molecules' (MW>500 Da) and the protein-bound compounds [11].

Recent reviews point out that removal of small watersoluble compounds is important for 'acute mortality' (e.g. related to hyperkalemia, sodium removal), but that for the chronic cardiovascular problems of the uremic syndrome, the protein-bound solutes and the middle molecules seem to play a more essential role [13-15]. Whereas the small water-soluble compounds, of which urea is the prototype, are easily removed by whatever dialysis strategy, the protein-bound toxins and middle molecules require more sophisticated strategies.

\section{The Toxicity of Middle Molecules}

Up till now, at least 40 middle molecules or groups of middle molecules have been identified [16]; a quantity far outnumbered, however, by the amount of as yet unidentified solutes (table 1) [12]. Many of these middle molecules have been linked to cardiovascular problems, either by being proinflammatory (advanced glycation end products, oxidation products, complement factor D, cytokines), by generating endothelial dysfunction or smooth muscle cell proliferation (endothelin, neuropeptide Y), by enhancing coagulation (cytokines, leptin), or by inducing a combination of some or all of the above.

New compounds are discovered regularly, such as recently uridine adenosine tetraphosphate, a very strong vasoconstrictive agent [17]. 
Table 1. Biochemically relevant middle molecules and protein, bound uremic solutes

Middle molecules
Adiponectin
Advanced glycation end products
Advanced oxidation products
$\beta_{2}$-microglobulin
Complement factor D
Dinucleoside polyphosphates
Cytokines
Endothelin
Immunoglobulin light chains
Leptin
Neuropeptide Y
Parathyroid hormone
Resistin
Protein-bound solutes
Asymmetric dimethylarginine
Homocysteine
Indoxyl sulfate
p-cresylsulfate
Phenylacetic acid

Apart from these, middle molecules have a toxic impact on other cell and organ systems than the cardiovascular system as well. In a recent series of comprehensive reviews of the present status in uremic toxicity, several chapters are devoted to middle molecules and their pathophysiologic role, especially $\beta_{2}$-microglobulin [18], resistin [19], adiponectin [20], the cytokines [21], leptin [22], immunoglobulin light chains [23], parathyroid hormone [24], the dinucleoside polyphosphates [25] and the advanced glycation end products [26].

As a consequence, to protect patients against the cardiovascular as well as other side effects of the uremic syndrome, it seems in accordance with our current pathophysiological concepts to pursue the removal of middle molecules as much as possible.

\section{Removal of the Middle Molecules}

Standard dialyzers with small pores (low-flux membranes) do not allow the transmembrane removal of middle molecules. This can be accomplished only by applying dialysis membranes with a large enough pore size (so-called high-flux membranes) [27]. Diffusive removal capacity is dependent on the MW of the compound [27], the intrinsic properties of the high-flux membrane [28], and the kinetic behavior of the middle molecule, which mostly is multicompartmental, resulting in dramatic rebound postdialysis [29].

Removal through large pores can be enhanced by applying convection, especially if used in a hemodiafiltration (HDF) setting [30]; the amount of cleared middle molecules is correlated to the quantity of plasma water removed and replaced in an equivoluminous manner [30]. The relative improvement in adequacy due to convection becomes more pronounced as the MW of the compounds to be removed increases, since the amount of convective clearance is independent of MW as long as membrane pore size is large enough to allow transfer [27]. Among convective strategies, both postdilution HDF and predilution hemofiltration are superior to predilution HDF for removal of middle molecules [31]. Of note, partial removal via the kidneys, as long as residual renal function is preserved [32], becomes relatively more important as the MW of the compounds to be removed increases and/or the molecules in question are difficult to remove by dialysis for other reasons (e.g. protein binding) [33]. As a consequence, dialytic strategies which preserve renal function, such as peritoneal dialysis (PD) [34] or high-flux hemodialysis [35], are preferable in this context. Total (urine plus dialysis) removal of $\beta_{2}$-microglobulin was, however, less substantial with PD than with high-flux hemodialysis [33].

Removal of the middle molecules can be further enhanced by increasing dialysis frequency or prolonging the dialysis session [36]. In a setting applying the Genius ${ }^{\circledR}$ dialysis system, which allows the collection of all spent dialysate and the manipulation of dialysis time without modifying any other element of the procedure (dialyzer characteristics, total displaced blood and dialysate volumes), $\beta_{2}$-microglobulin removal increased almost 2fold, only by increasing dialysis time from 4 to $8 \mathrm{~h}$, in spite of an unaltered $\mathrm{Kt} / \mathrm{V}_{\text {urea }}$ [37]. The reason for this observation is that more time is allowed for $\beta_{2}$-microglobulin, with its multicompartmental behavior, to move from the extravascular to the intravascular compartment, from where it can be removed by the dialysis procedure.

In a subanalysis of the HEMO study, mortality was inversely related to $\beta_{2}$-microglobulin concentration [38], an association essentially confined to infectious complications [39]. Of note, $\beta_{2}$-microglobulin levels are not only the result of clearance but also of inflammation, another hallmark of uremic toxicity. As such, it should be considered to use $\beta_{2}$-microglobulin levels as a marker of dialysis efficiency. 


\section{The Toxicity of Protein-Bound Molecules}

Also many protein-bound molecules (table 1) have been linked to cardiovascular problems, either through a proinflammatory impact ( $p$-cresylsulfate) [40] or by causing endothelial or other vascular dysfunction (indoxyl sulfate, phenylacetic acid) [41, 42]. The concentration of $p$-cresol, the hydrolytic degradation product of $p$-cresylsulfate, is related to overall and cardiovascular mortality in dialysis patients $[43,44]$ as well as to the development of infection [45].

Next to the middle molecules, the comprehensive review on uremic toxicity mentioned above also devoted attention to the protein-bound solutes homocysteine [46], indoxyl sulfate [47, 48], and p-cresylsulfate [47] as well as to protein-bound solutes in general [47]. Of note, several of the middle molecules are protein bound as well (leptin, the cytokines, the advanced glycation end products, the dinucleoside polyphosphates). Also asymmetric dimethylarginine, a solute with substantial hemodynamic effects [49], has been considered to be protein bound [50].

In view of these pathophysiological considerations, the removal of protein-bound molecules also should be pursued in end-stage renal disease.

\section{Removal of Protein-Bound Uremic Solutes}

In contrast to what is observed for the middle molecules, high-flux hemodialysis has no considerable impact on the removal of the protein-bound solutes [51]. Among the options for convective strategies, postdilution HDF is superior to both predilution HDF and predilution hemofiltration [31]. This observation, together with the findings for $\beta_{2}$-microglobulin mentioned above and a better removal capacity for the small water-soluble compounds, makes postdilution HDF the most efficient convective option for all uremic retention solutes together [31].

Daily hemodialysis was shown to decrease the predialysis concentration of protein-bound solutes, as compared to a classical alternate day dialysis regime [52].

PD was shown, a bit counterintuitively, to be inferior to high-flux hemodialysis in removing protein-bound molecules, in spite of a better preserved residual renal function and considerable transperitoneal albumin loss $[33,53]$. Remarkably, however, in spite of this lower removal with PD, plasma concentrations of protein-bound solutes were also lower in PD patients, pointing to possible differences in intestinal generation and/or metabo- lism [54]. Whatever the mechanisms, since plasma concentration determines toxicity, the latter finding seems to be pathophysiologically more relevant than the lower clearance with PD.

Much is expected from adsorptive strategies to enhance removal of the protein-bound solutes [10]. One option is fractionated plasma separation and adsorption (Prometheus ${ }^{\circledR}$ ). Indeed, a pilot study showed effective removal of protein-bound solutes [55] but was hampered by troublesome coagulation problems [56]. Removal of protein-bound solutes was also enhanced by adding sorbent to the dialysate [57].

\section{Interventional Outcome Studies Based on Removal}

Based on the data mentioned above, the question has been raised in how far improving the removal of the middle molecules and/or the protein-bound solutes could have an impact on the outcome of patients treated by hemodialysis or related strategies.

As the removal of the protein-bound molecules is cumbersome, no interventional trials with extracorporeal strategies focusing on these compounds have been undertaken so far.

AST-120 (Kremezin $\left.{ }^{\circledR}\right)$ is an intestinal sorbent with the capacity to decrease plasma concentration of indoxyl sulfate [58] and maybe other protein-bound uremic solutes such as the cresols as well [59]; AST-120 was shown in animal experiments to prevent progression of kidney injury and glomerulosclerosis $[60,61]$ and in a number of interventional trials, it improved clinical outcome parameters [62, 63].

As removal of middle molecules can easily be achieved by large-pore high-flux dialysis, much more outcome data on this topic are available. A number of retrospective trials and secondary analyses of randomized controlled trials (RCTs) have shown survival superiority for the high-flux membranes in a hemodialysis setting, as compared to low-flux membranes. The HEMO study, a 4-arm RCT also comparing low-flux and high-flux membranes, demonstrated a nonsignificant trend in favor of high-flux membranes [64], which became significant at subanalysis, either focusing on cardiovascular rather than global outcome or on patients enrolled in the study after several years of preceding dialysis $[65,66]$. Interpretation of the HEMO study is hampered, however, by the recruitment of prevalent patients, and by the application of dialyzer reuse and short dialysis times [67]. 
The Membrane Permeability Outcome (MPO) study, a recently published RCT, demonstrated survival outcome superiority of high-flux dialysis in dialysis patients with a serum albumin $<4 \mathrm{~g} / \mathrm{dl}$ at inclusion [68]. At secondary analysis, high-flux dialysis was also associated with superior outcomes in diabetics [68]. Of note, a substantial fraction of the current hemodialysis population is hypoalbuminemic and/or diabetic $[69,70]$.

The study protocol of the MPO study had originally been developed for hypoalbuminemic patients only [71]; because the enrollment was slower than expected, normoalbuminemic subjects were allowed to enter the study more than 1 year after enrollment started. As a consequence, hardly $24 \%$ of included patients were normoalbuminemic. When both hypoalbuminemic and normoalbuminemic patients were considered together, however, the survival advantage for high-flux membranes seen in hypoalbuminemic patients was not corroborated.

Interventional outcome studies using convective strategies are still ongoing [72]. One small trial, comparing on-line hemofiltration to low-flux dialysis illustrated a survival superiority for hemofiltration [73]. However, only 2 groups of 32 subjects were randomized into this study, of which only 11 subjects per group finished the 3 year follow-up period.

In brief, a number of recent data suggest an improvement of outcomes when increasing membrane pore size in a hemodialysis setting; the differences were each time found in subgroups of the studied populations. Whether adding convection results in a supplementary benefit has still not entirely been proven in well-conceived RCTs, although indirect arguments, such as the relation between $\beta_{2}$-microglobulin concentration and outcome [38], as well as pathophysiological evidence accumulated over time $[10,14,15]$ plead in favor of this strategy.

One issue of concern may be that with these highly efficient methods, protective substances may be removed actively together with deleterious uremic toxins. However, uremic retention results in an overall dysfunction of most organ systems suggesting an overriding effect of the deleterious compounds on the beneficial ones. In addition, removal even with the most efficient methods is far from complete or comparable to that of healthy kidneys; hence, it is unlikely that current dialysis is effective enough to create a deleterious impact by removing too many protective compounds. If such losses would indeed be clinically relevant, one would expect an outcome advantage for the less efficient (low-flux) methods. To the best of our knowledge, such evidence has not been delivered.

Advantages of New Hemodialysis

Membranes and Equipment

\section{Dialysis Water Purity}

Increasing dialyzer pore size as well as the application of on-line HDF carries the risk of transferring dialysate impurities into the blood stream [74]. Hence, a regular control for dialysate purity is necessary and also advised by the European Best Practice Guidelines, although their recommendation remains limited only to an evaluation for intact bacteria and one single proinflammatory microbial degradation product, intact endotoxin, by means of the limulus amebocyte lysate (LAL) test [75]. Bacteria, especially those known to contaminate dialysate, however, produce many other products such as peptidoglycans or oligodeoxynucleotides, which are not registered by the LAL test [76]. In a recent study it was shown that approximately $10 \%$ of dialysate samples classified as ultrapure according to the accepted criteria still contained components with significant proinflammatory capacity, if tested with a method also sensitive to other proinflammatory agents than intact endotoxin [77]. It is therefore compulsory, in our opinion, that in case of high-flux hemodialysis, and even more in the case of on-line HDF, dialysate be tested for proinflammmatory contaminants on a regular basis, and preferentially by a biological test method which is sensitive to more than intact endotoxin alone [77].

\section{Prevention of Intradialytic Hypotension}

Fluid removal in hemodialysis patients is essential since both over- and underhydration are linked to morbidity. An important problem is the occurrence of hypotensive episodes when fluid is removed too quickly and ultrafiltration surpasses refill from the interstitium, resulting in hemoconcentration. As of today, several hemodialysis machines contain devices allowing blood volume measurement (BVM) [78]. BVM allows intervening once hemoconcentration exceeds a certain alarm threshold to prevent timely symptoms of hypovolemia. Many current dialysis machines contain biofeedback systems transferring BVM information to devices modifying elements of the dialysis strategy, e.g. ultrafiltration rate. However, when tested in clinical trials, there were no outcome differences in favor of BVM $[79,80]$.

In addition to ultrafiltration control, hypotensive episodes can also be prevented by sodium profiling [81] or by cooling of the dialysate [82]. Although in some studies sodium profiling had a clinical benefit, in general also a positive sodium balance accompanies this intervention, resulting in inevitable disadvantages such as increased 
interdialytic weight gain and a subsequent need for more ultrafiltration. Since cooling of dialysate does not have the same disadvantages, whereas it prevents hypotension even in a more efficacious way than sodium profiling [82], it is the preferred option among both modalities. Nevertheless, all these technical gadgets do not outweigh the fact that the simplest way to avoid intradialytic hypotension is to extend treatment time.

\section{Home Hemodialysis}

During the last few years there has been a resurgence of home hemodialysis both in Europe and the United States. The availability of simpler dialysis equipment has certainly facilitated this evolution. Application of hemodialysis at home allows more flexibility than in-hospital hemodialysis, with daily dialysis and prolonged dialysis as more easily applicable options. In a recent study, survival of daily nocturnal home hemodialysis was comparable to that of kidney transplant recipients, pointing to the clinical potential of such a strategy [83].

\section{Conclusions}

Uremic toxicity and especially cardiovascular complications are to a large extent mediated by middle molecules and protein-bound molecules. Dialytic removal of middle molecules can be increased by the use of high-flux membranes. This removal can be further enhanced by addition of convection. The data for protein-bound solutes remain less convincing, with postdilution HDF being the most efficient of the available convective strategies.

A number of studies suggest that outcome improves with dialysis on high-flux membranes. Observational data are in favor of convection, but strength of evidence is low. High-flux dialysis and on-line HDF should be coupled to a careful control of dialysate purity, including a broader range of potential contaminants than intact endotoxin alone.

\section{References}

1 Vanholder R, De Smet R: Pathophysiologic effects of uremic retention solutes. J Am Soc Nephrol 1999;10:1815-1823.

-2 Lindner A, Charra B, Sherrard DJ, Scribner $\mathrm{BH}$ : Accelerated atherosclerosis in prolonged maintenance hemodialysis. N Engl J Med 1974;290:697-701.

3 Foley RN, Parfrey PS, Sarnak MJ: Clinical epidemiology of cardiovascular disease in chronic renal disease. Am J Kidney Dis 1998; 32:112-119.

-4 Vanholder R, Massy Z, Argiles A, Spasovski G, Verbeke F, Lameire N: Chronic kidney disease as cause of cardiovascular morbidity and mortality. Nephrol Dial Transplant 2005;20:1048-1056.

-5 Van Biesen W, De Bacqer D, Verbeke F, Delanghe J, Lameire N, Vanholder R: The glomerular filtration rate in an apparently healthy population and its relation with cardiovascular mortality during 10 years. Eur Heart J 2007;28:478-483.

6 6 Levey AS, Eckardt KU, Tsukamoto Y, et al: Definition and classification of chronic kidney disease: a position statement from Kidney Disease: Improving Global Outcomes (KDIGO). Kidney Int 2005;67:2089-2100.

$7 \mathrm{~K} / \mathrm{DOQI}$ clinical practice guidelines for chronic kidney disease: evaluation, classification, and stratification. Am J Kidney Dis 2002;39:1-266
8 Coresh J, Selvin E, Stevens LA, et al: Prevalence of chronic kidney disease in the United States. JAMA 2007;298:2038-2047.

-9 Cheung AK, Sarnak MJ, Yan G, et al: Atherosclerotic cardiovascular disease risks in chronic hemodialysis patients. Kidney Int 2000;58:353-362.

10 Vanholder R, Baurmeister U, Brunet P, Cohen G, Glorieux G, Jankowski J: A bench to bedside view of uremic toxins. J Am Soc Nephrol 2008;19:863-870.

-11 Vanholder R, De Smet R, Glorieux G, et al Review on uremic toxins: classification, concentration, and interindividual variability. Kidney Int 2003;63:1934-1943.

12 Weissinger EM, Kaiser T, Meert N, et al: Proteomics: a novel tool to unravel the pathophysiology of uraemia. Nephrol Dial Transplant 2004;19:3068-3077.

13 Vanholder R, Van Laecke S, Glorieux G: What is new in uremic toxicity? Pediatr Nephrol 2008;23:1211-1221.

14 Vanholder R, Argiles A, Baurmeister U, et al: Uremic toxicity: present state of the art. Int J Artif Organs 2001;24:695-725.

15 Vanholder R, Van Laecke S, Verbeke F, Glorieux G, Van Biesen W: Uraemic toxins and cardiovascular disease: in vitro research versus clinical outcome studies. Nephrol Dial Transplant Plus 2008;1:2-10.
16 Vanholder R, Van Laecke S, Glorieux G: The middle-molecule hypothesis 30 years after: lost and rediscovered in the universe of uremic toxicity? J Nephrol 2008;21:146-160.

$\checkmark 17$ Jankowski V, Tolle M, Vanholder R, et al: Uridine adenosine tetraphosphate: a novel endothelium- derived vasoconstrictive factor. Nat Med 2005;11:223-227.

18 Drüeke TB, Massy ZA: Beta2-microglobulin. Sem Dial 2009;22:378-380.

19 Cohen G, Hörl WH: Resistin as a cardiovascular and atherosclerotic risk factor and uremic toxin. Sem Dial 2009;22:373-377.

20 Adamczak M, Chudek J, Wiecek A: Adiponectin in patients with chronic kidney disease. Sem Dial 2009;22:391-395.

21 Carrero JJ, Park SH, Axelsson J, Lindholm B, Stenvinkel P: Cytokines, atherogenesis and hypercatabolism in chronic kidney disease: a dreadful triad. Sem Dial 2009;22:381-386.

22 Yamamoto T, Carrero JJ, Lindholm B, Stenvinkel P, Axelsson J: Leptin and uremic protein-energy wasting - the axis of eating. Sem Dial 2009;22:387-390.

-23 Cohen G, Hörl WH: Free immunoglobulin light chains as a risk factor in renal and extrarenal complications. Sem Dial 2009;22: 369-372.

24 Rodriguez M, Lorenzo V: Parathyroid hormone, a uremic toxin. Sem Dial 2009;22: 363-368. 
-25 Jankowski V, Günther T H-RS, Zidek W, Jankowski J: Dinucleoside polyphosphates and uremia. Sem Dial 2009;22:396-399.

-26 Thornalley PJ, Rabbani N: Highlights and hotspots of protein glycation in end stage renal disease. Sem Dial 2009;22:400-404.

-27 Maduell F, Navarro V, Cruz MC, et al: Osteocalcin and myoglobin removal in on-line hemodiafiltration versus low- and high-flux hemodialysis. Am J Kidney Dis 2002;40: 582-589.

-28 Ouseph R, Hutchison CA, Ward RA: Differences in solute removal by two high-flux membranes of nominally similar synthetic polymers. Nephrol Dial Transplant 2008;23: 1704-1712.

-29 Leypoldt JK, Cheung AK, Deeter RB: Rebound kinetics of beta2-microglobulin after hemodialysis. Kidney Int 1999;56:15711577.

-30 Lornoy W, Becaus I, Billiouw JM, Sierens L, Van Malderen P, D'Haenens P: On-line haemodiafiltration. Remarkable removal of beta2-microglobulin. Long-term clinical observations. Nephrol Dial Transplant 2000; 15(suppl 1):49-54.

-31 Meert N, Eloot S, Waterloos MA, et al: Effective removal of protein-bound uraemic solutes by different convective strategies: a prospective trial. Nephrol Dial Transplant 2009; 24:562-570

-32 Vanholder RC, Ringoir SM: Adequacy of dialysis: a critical analysis. Kidney Int 1992;42: 540-558.

$\checkmark 33$ Evenepoel P, Bammens B, Verbeke K, Vanrenterghem Y: Superior dialytic clearance of beta(2)-microglobulin and $p$-cresol by highflux hemodialysis as compared to peritoneal dialysis. Kidney Int 2006;70:794-799.

-34 Moist LM, Port FK, Orzol SM, et al: Predictors of loss of residual renal function among new dialysis patients. J Am Soc Nephrol 2000;11:556-564.

- 35 McKane W, Chandna SM, Tattersall JE, Greenwood RN, Farrington K: Identical decline of residual renal function in high-flux biocompatible hemodialysis and CAPD. Kidney Int 2002;61:256-265.

>36 Raj DS, Ouwendyk M, Francoeur R, Pierratos A: beta(2)-microglobulin kinetics in nocturnal haemodialysis. Nephrol Dial Transplant 2000;15:58-64.

-37 Eloot S, Van Biesen W, Dhondt A, et al: Impact of hemodialysis duration on the removal of uremic retention solutes. Kidney Int 2008;73:765-770

>38 Cheung AK, Rocco MV, Yan G, et al: Serum beta-2 microglobulin levels predict mortality in dialysis patients: results of the HEMO study. J Am Soc Nephrol 2006;17:546-555.

>39 Cheung AK, Greene T, Leypoldt JK, et al: Association between serum 2-microglobulin level and infectious mortality in hemodialysis patients. Clin J Am Soc Nephrol 2008;3: 69-77.
40 Schepers E, Meert N, Glorieux G, Goeman J, Van der Eycken J, Vanholder R: P-cresylsulphate, the main in vivo metabolite of $p$-cresol, activates leucocyte free radical production. Nephrol Dial Transplant 2007;22: 592-596.

41 Faure V, Dou L, Sabatier F, et al: Elevation of circulating endothelial microparticles in patients with chronic renal failure. J Thromb Haemost 2006;4:566-573.

42 Jankowski J, van der Giet M, Jankowski V, et al: Increased plasma phenylacetic acid in patients with end-stage renal failure inhibits iNOS expression. J Clin Invest 2003;112 256-264.

-43 Meijers BK, Bammens B, De Moor B, Verbeke K, Vanrenterghem Y, Evenepoel P: Free $p$-cresol is associated with cardiovascular disease in hemodialysis patients. Kidney Int 2008;73:1174-1180.

44 Bammens B, Evenepoel P, Keuleers H, Verbeke K, Vanrenterghem Y: Free serum concentrations of the protein-bound retention solute $p$-cresol predict mortality in hemodialysis patients. Kidney Int 2006;69:10811087.

45 De Smet R, Van Kaer J, Van Vlem B, et al: Toxicity of free $p$-cresol: a prospective and cross-sectional analysis. Clin Chem 2003;49: 470-478.

46 Perna AF, Ingrosso D, Violetti E, et al: Hyperhomocysteinemia in uremia - red flag in a disrupted circuit. Sem Dial 2009;22:351356.

47 Jourde-Chiche N, Dou L, Cerini C, DignatGeorge F, Vanholder R, Brunet P: Protein bound toxins - update 2009. Sem Dial 2009; 22:334-339.

-48 Barreto FC, Barreto DV, Liabeuf S, Drüeke TB, Massy ZA: Effects of uremic toxins on vascular and bone remodelling. Sem Dial 2009;22:433-437.

49 Kielstein JT, Impraim B, Simmel S, et al: Cardiovascular effects of systemic nitric oxide synthase inhibition with asymmetrical dimethylarginine in humans. Circulation 2004;109:172-177.

50 Kielstein JT, Boger RH, Bode-Boger SM, et al: Low dialysance of asymmetric dimethylarginine (ADMA) - in vivo and in vitro evidence of significant protein binding. Clin Nephrol 2004;62:295-300.

51 Lesaffer G, De SR, Lameire N, Dhondt A, Duym P, Vanholder R: Intradialytic removal of protein-bound uraemic toxins: role of solute characteristics and of dialyser membrane. Nephrol Dial Transplant 2000;15:50 57.

52 Fagugli RM, De Smet R, Buoncristiani U, Lameire N, Vanholder R: Behavior of non-protein-bound and protein-bound uremic solutes during daily hemodialysis. Am J Kidney Dis 2002;40:339-347.
53 Pham NM, Recht NS, Hostetter TH, Meyer TW: Removal of the protein-bound solutes indican and $p$-cresol sulfate by peritoneal dialysis. Clin J Am Soc Nephrol 2008;3:8590.

54 Vanholder R, Meert N, Van Biesen W, et al: Why do patients on peritoneal dialysis have low blood levels of protein-bound solutes? Nat Clin Pract Nephrol 2009;5:130-131.

55 Meijers BK, Weber V, Bammens B, et al: Removal of the uremic retention solute $p$-cresol using fractionated plasma separation and adsorption. Artif Organs 2008;32:214-219.

56 Meijers BK, Verhamme P, Nevens F, et al: Major coagulation disturbances during fractionated plasma separation and adsorption. Am J Transplant 2007;7:2195-2199.

57 Meyer TW, Peattie JW, Miller JD, et al: Increasing the clearance of protein-bound solutes by addition of a sorbent to the dialysate. J Am Soc Nephrol 2007;18:868-874.

58 Schulman G, Agarwal R, Acharya M, Berl T, Blumenthal S, Kopyt N: A multicenter, randomized, double-blind, placebo-controlled, dose-ranging study of AST-120 (Kremezin) in patients with moderate to severe CKD. Am J Kidney Dis 2006;47:565-577.

59 Niwa T, Ise M, Miyazaki T, Meada K: Suppressive effect of an oral sorbent on the accumulation of $p$-cresol in the serum of experimental uremic rats. Nephron 1993;65: 82-87.

60 Aoyama I, Shimokata K, Niwa T: Oral adsorbent AST-120 ameliorates interstitial fibrosis and transforming growth factor-beta(1) expression in spontaneously diabetic (OLETF) rats. Am J Nephrol 2000;20:232-241.

61 Niwa T, Ise M: Indoxyl sulfate, a circulating uremic toxin, stimulates the progression of glomerular sclerosis. J Lab Clin Med 1994; 124:96-104.

62 Ueda H, Shibahara N, Takagi S, Inoue T, Katsuoka Y: AST-120 treatment in pre-dialysis period affects the prognosis in patients on hemodialysis. Ren Fail 2008;30:856-860.

63 Ueda H, Shibahara N, Takagi S, Inoue T, Katsuoka Y: AST-120, an oral adsorbent, delays the initiation of dialysis in patients with chronic kidney diseases. Ther Apher Dial 2007;11:189-195.

-64 Eknoyan G, Beck GJ, Cheung AK, et al: Effect of dialysis dose and membrane flux in maintenance hemodialysis. N Engl J Med 2002;347:2010-2019.

65 Delmez JA, Yan G, Bailey J, et al: Cerebrovascular disease in maintenance hemodialysis patients: results of the HEMO Study. Am J Kidney Dis 2006;47:131-138.

66 Cheung AK, Levin NW, Greene T, et al: Effects of high-flux hemodialysis on clinical outcomes: results of the HEMO study. J Am Soc Nephrol 2003;14:3251-3263.

67 Locatelli F, Gauly A, Czekalski S, et al: The MPO Study: just a European HEMO Study or something very different? Blood Purif 2008;26:100-104. 
68 Locatelli F, Martin-Malo A, Hannedouche T, et al: Effect of membrane permeability on survival of hemodialysis patients. J Am Soc Nephrol 2009;20:645-654.

69 Rayner HC, Pisoni RL, Bommer J, et al: Mortality and hospitalization in haemodialysis patients in five European countries: results from the Dialysis Outcomes and Practice Patterns Study (DOPPS). Nephrol Dial Transplant 2004;19:108-120.

70 Lopes AA, Elder SJ, Ginsberg N, et al: Lack of appetite in haemodialysis patients-associations with patient characteristics, indicators of nutritional status and outcomes in the international DOPPS. Nephrol Dial Transplant 2007;22:3538-3546.

71 Locatelli F, Hannedouche T, Jacobson S, et al: The effect of membrane permeability on ESRD: design of a prospective randomised multicentre trial. J Nephrol 1999;12:85-88.

72 Penne EL, Blankestijn PJ, Bots ML, et al: Effect of increased convective clearance by on-line hemodiafiltration on all cause and cardiovascular mortality in chronic hemodialysis patients - the Dutch CONvective TRAnsport STudy (CONTRAST): rationale and design of a randomised controlled trial [ISRCTN38365125]. Curr Control Trials Cardiovasc Med 2005;6:8.
73 Santoro A, Mancini E, Bolzani R, et al: The effect of on-line high-flux hemofiltration versus low-flux hemodialysis on mortality in chronic kidney failure: a small randomized controlled trial. Am J Kidney Dis 2008;52 507-518.

74 Vanholder R, Van Haecke E, Veys N, Ringoir $\mathrm{S}$ : Endotoxin transfer through dialysis membranes: small- versus large-pore membranes. Nephrol Dial Transplant 1992;7:333-339.

75 European Best Practice Guidelines for Haemodialysis: Dialysis water purity. Nephrol Dial Transplant 2002;17(suppl 7):45-62.

76 Schindler R, Beck W, Deppisch R, et al: Short bacterial DNA fragments: detection in dialysate and induction of cytokines. J Am Soc Nephrol 2004;15:3207-3214.

77 Glorieux G, Schepers E, Schindler R, et al: A novel bio-assay increases the detection yield of microbiological impurity of dialysis fluid, in comparison to the LAL-test. Nephrol Dial Transplant 2009;24:548-554

78 Davenport A: Can advances in hemodialysis machine technology prevent intradialytic hypotension? Semin Dial 2009;22:231-236.
79 Andrulli S, Colzani S, Mascia F, et al: The role of blood volume reduction in the genesis of intradialytic hypotension. Am J Kidney Dis 2002;40:1244-1254

80 Reddan DN, Szczech LA, Hasselblad V, et al: Intradialytic blood volume monitoring in ambulatory hemodialysis patients: a randomized trial. J Am Soc Nephrol 2005;16: 2162-2169.

>81 Song JH, Park GH, Lee SY, Lee SW, Lee SW, Kim MJ: Effect of sodium balance and the combination of ultrafiltration profile during sodium profiling hemodialysis on the maintenance of the quality of dialysis and sodium and fluid balances. J Am Soc Nephrol 2005; 16:237-246

-82 Davenport A, Cox C, Thuraisingham R: The importance of dialysate sodium concentration in determining interdialytic weight gains in chronic hemodialysis patients: the PanThames Renal Audit. Int J Artif Organs 2008;31:411-417.

83 Pauly RP, Gill JS, Rose CL, Asad RA, Chery A, Pierratos A, Chan CT: Survival among nocturnal home haemodialysis patients compared to kidney transplant recipients. Nephrol Dial Transplant 2009;24:29152919.

\title{
Editorial Comment
}

\author{
M. El Nahas, Sheffield
}

The minireview by Vanholder and colleagues from Ghent seeks to find the 'Holy Grail' of hemodialysis, namely uremic toxin(s), and best approaches to remove them. The authors review a whole new range of putative toxins. It is interesting for those of us who have been around for a while how each generation of successive uremic toxin 'detectives' identifies new mediators and postulates better ways of removing them. It is also intriguing and disappointing that most dialytic modalities put forward, as well as pharmacological interventions in haemodialysis patients, fail to fulfil their promises. Intensified hemodialysis and high-flux membranes are no exception as the HEMO and the MPO studies failed to show benefit for these respective interventions. However, a subgroup analysis suggested benefit in the MPO study for diabetics and those with low albumin. Subgroup and post hoc analyses have to be viewed with caution as the studies were not powered to address the questions these analyses pretend to answer! Longer dialysis hours with conventional membranes leading to optimisation of water and sodium removal have also shown great promise. Perhaps, and after all, water and sodium are the most harmful of uremic toxins?! 